INTERNACIONAL

\title{
La arbitrariedad del proceso sumarísimo de expulsión: Análisis de la reforma migratoria argentina a la luz del sistema interamericano de derechos humanos
}

\author{
The arbitrariness of the summary expulsion process: Analysis of the Argentine \\ immigration reform in the light of the Inter-American Human Rights System
}

\section{Víctor Lisandro Elías}

Universidad de Buenos Aires, Argentina

\begin{abstract}
RESUMEN El 30 de enero de 2017, el Poder Ejecutivo argentino dictó un Decreto de Necesidad y Urgencia 70/PEN/17 modificando la Ley de Migraciones (Ley 25.871), considerada un instrumento modelo en materia de garantía de los derechos humanos de las personas migrantes. Ante ello, organizaciones de la sociedad civil respondieron mediante la presentación de un amparo colectivo, en cuya instancia de apelación se resolvió la invalidez constitucional. Hoy, las personas migrantes en Argentina esperan el pronunciamiento de la Corte Suprema de Justicia de la Nación. Más allá de los fundamentos materiales para su promulgación -ampliamente cuestionados-, la norma introduce numerosas modificaciones a los procedimientos establecidos en la Ley de Migraciones, que implican un retroceso en el acceso a los derechos del colectivo de migrantes en Argentina. Interesan en particular las vicisitudes en el marco de los procesos de expulsión, ahora de carácter sumarísimo, y su impacto en el respeto y garantías sin discriminación de los derechos establecidos en la Convención Americana sobre Derechos Humanos al debido proceso (artículo 8) y al acceso a la justicia (artículo 25) de las personas migrantes afectadas.
\end{abstract}

PALABRAS CLAVE Migrantes, derechos humanos, Argentina, expulsión.

ABSTRACT On January 30, 2017, the Argentine Executive Branch issued a Decree of Necessity and Urgency 70/PEN/17, modifying the Migration Law (Law 25,871), considered a model in terms of guarantee of human rights of migrants. In response, civil society organizations responded by submitting a collective amparo injunction, in whose appeal they resolved its constitutional disability. Today, migrants in Argentina await the pronouncement of the Supreme Court of Justice of the Nation. Beyond the material 


\begin{abstract}
foundations for its promulgation (widely questioned), the rule introduces numerous modifications to the procedures established in the Migration Law, which imply a setback in the access to the rights of the migrants in Argentina. Of particular interest are the vicissitudes in the context of the expulsion proceedings, now of a very summary nature, and their impact on the respect and guarantees without discrimination of the rights established in the American Convention on Human Rights, right to due process (Article 8) and right of access to justice (Article 25) of the affected migrants.
\end{abstract}

KEYWORDS Migrants, human rights, Argentina, expulsion.

\title{
Introducción
}

El 30 de enero de 2017, el Poder Ejecutivo argentino dictó el Decreto de Necesidad y Urgencia $70 / \mathrm{PEN} / 17,{ }^{1}$ que modifica la Ley de Migraciones (Ley 25.871), considerada un instrumento modelo en la garantía de los derechos de las personas migrantes (Ceriani, 2011: 76; Hines, 2010: 472; Nicolao, 2010: 224). Ante ello, las organizaciones de la sociedad civil presentaron un amparo colectivo, cuya instancia de apelación resolvió por la inconstitucionalidad de la reforma. ${ }^{2}$ Hoy, las personas migrantes en la Argentina esperan el pronunciamiento de la Corte Suprema de Justicia de la Nación. ${ }^{3}$

Más allá de los fundamentos materiales para su promulgación —ampliamente cuestionados (Barbero, 2018: 13-15; Basok, 2017: 7; Canelo, Gavazzo y Nejamkis 2018: 165-167; González y Tavernelli, 2018: 85) —, la norma introduce numerosas modificaciones a los procedimientos establecidos en la Ley de Migraciones que implican un retroceso en el acceso a los derechos del colectivo de migrantes en la Argentina.

Interesan en particular las vicisitudes en el marco de los procesos de expulsión, ahora de carácter sumarísimo, y su impacto en el respeto y garantías sin discriminación de los derechos establecidos en la Convención Americana sobre Derechos $\mathrm{Hu}$ manos (CADH) al debido proceso y al acceso a la justicia de las personas migrantes afectadas.

Este análisis no es un mero ejercicio académico intelectual, sino que responde a la aplicación del control de convencionalidad por parte de todas las reparticiones del poder público en Argentina, obligación reiterada por la Corte Interamericana de Derechos Humanos (Corte IDH).

\footnotetext{
1. Los Decreto de Necesidad y Urgencia (DNU) son una herramienta regulada en el artículo 99 inciso tercero de la Constitución Nacional (Avalos, 2012).

2. Causa 3061/2017, sentencia del 22 de marzo de 2018.

3. Causa 3061/2017/CA1, resolución del 21 de junio de 2018.
} 


\section{La Ley de Migraciones y las modificaciones introducidas por el DNU 70/17}

La Ley de Migraciones - que vino a poner fin a la denominada «ley Videla», manifiestamente violatoria de los derechos de las personas migrantes (Mendos y Muñoz, 2012: 208) - fue producto de un profundo proceso de reforma legislativa que tenía como objetivo abandonar la doctrina de la seguridad nacional que concebía al migrante como un enemigo, hacia un modelo que integrase a los migrantes al cuerpo social en un plano de igualdad con los nacionales (Nejamkis, 2012). Durante este período, el proceso tuvo como protagonista el caso de Juan Carlos de la Torre, ante la Comisión Interamericana de Derechos Humanos (CIDH), cuya solución amistosa se basó en la reforma de la ley migratoria argentina. ${ }^{4}$

Uno de los rasgos más característicos de la Ley de Migraciones fue el reconocimiento del derecho a migrar como un derecho humano (artículo 4) (González y Tavernelli, 2018: 82; Hines, 2010: 488). Este reconocimiento resulta de gran importancia, ya que ni la CADH ni los instrumentos del sistema universal establecen a la migración como un derecho humano en dichos términos (García, 2013: 39). Por ello, es posible afirmar que el texto de la Ley de Migraciones fue construido a partir de la garantía de un derecho humano superador relacionado con las disposiciones de los tratados internacionales, los cuales solo receptan un núcleo básico de protección mínimo, ya que su aplicación no depende del reconocimiento de un derecho a migrar, sino de estándares generales de protección (García, 2013: 44).

En esa inteligencia, la ley estableció inicialmente un sistema ajustado a los requisitos del sistema interamericano de derechos humanos (Hines, 2010: 509), mediante el cual cualquier persona que presentara alguno de los supuestos de impedimento de permanencia en el país que pudieran derivar en su expulsión tenía la oportunidad de acceder a una serie de recursos administrativos y judiciales para que, en un plazo razonable, se resolviera su situación (artículo 29). De esta manera, una persona migrante notificada de su situación de irregularidad contaba en sede administrativa, ante la Dirección Nacional de Migraciones (DNM), con tres herramientas de revisión: un recurso de reconsideración, un recurso jerárquico, y un recurso de alzada. El plazo de interposición de los dos primeros era de diez y quince días hábiles desde el momento de la notificación de la disposición que declaraba la situación de irregularidad (artículos 75 a 79). A su vez, la persona tenía diez días para interponer el recurso de alzada, que sería resuelto por el Ministerio del Interior, del cual depende la DNM. Agotada la vía administrativa, la persona contaba con 30 días para interponer la acción judicial correspondiente (artículo 84).

Vale la pena aclarar que, en todos los supuestos de impedimento, la DNM y el Mi-

4. Caso Juan Carlos de la Torre contra Argentina, Comisión Interamericana de Derechos Humanos. Disponible en https://www.oas.org/es/cidh/decisiones/2011/ARSA12306ES.doc. 
nisterio del Interior podían otorgar la dispensa por razones de unidad familiar, 5 obteniendo excepcionalmente la venia para permanecer en el país en calidad migratoria regular (artículo 29 in fine). Por otro lado, la Ley de Migraciones establecía que toda persona que careciera de recursos económicos podía solicitar la asistencia letrada gratuita, sin más requisitos que dicha declaración (artículos 29 y 86).

El DNU 70/17 no solo presenta un recorte de garantías sustancial de los derechos de las personas migrantes (Barbero, 2018: 3; Carril, 2018: 199), sino que a su vez estableció el «Procedimiento migratorio especial sumarísimo», aplicable a casi todos los supuestos de impedimento de permanencia en el país. ${ }^{6}$

Conforme este nuevo procedimiento, la vía administrativa se considera agotada solo con el recurso jerárquico, para cuya interposición el migrante cuenta con tres días hábiles desde la notificación de su situación de irregularidad (artículo 14 del DNU 70/17). Este plazo se suspende por una única vez con la toma de vista del expediente durante tres días hábiles (artículo 13). Luego de agotada la vía administrativa y notificada la respuesta, la persona puede apelar en sede judicial en un plazo de tres días hábiles (artículo 16). El mismo plazo se estipula para la apelación ante la segunda instancia, luego de la cual quedará firme (o no) la medida solicitada por la DNM (artículo 18). Es decir, se aprecia una notable reducción de los tiempos para que la persona migrante pueda defender su permanencia en el país.

Asimismo, la dispensa por motivos de unidad familiar queda limitada a un pequeño grupo de impedimentos y no puede ser sujeta a revisión judicial, pues es facultad exclusiva y discrecional de la DNM (artículos 4 y 7 ).

Por último, a esta situación debe sumarse que cualquier pedido de asistencia jurídica gratuita debe ir acompañado de la documentación respaldatoria que acredite la falta de recursos. ${ }^{7}$

\section{La especial situación de vulnerabilidad del colectivo migrante}

Hace más de quince años, la Corte IDH tuvo la oportunidad de referirse al preocupante estado de las personas migrantes en la región. En este sentido, concluyó que se encuentran en una situación de vulnerabilidad, la cual «tiene una dimensión ideo-

5. Esta dispensa tiene el objeto de proteger la vida familiar y el interés superior del niño, niña o adolescente.

6. El procedimiento sumarísimo (artículo 69 de la Ley 25.871) abarca aquellos casos de personas migrantes que presentaron documentación falsa, se encontraran involucradas en delitos o hubieren ingresado al territorio eludiendo el control migratorio (artículo 29 incisos a-k y artículo 62 incisos a, b, c y f) y a los restantes supuestos de los artículos 29 y 62 que impliquen gravedad institucional.

7. Los documentos dispuestos por la Disposición DNM 165/14 para demostrar tales extremos son un informe social, una carta de pobreza o un certificado consular que acredite la situación de pobreza. Todos ellos, en la práctica, demoran un tiempo superior a los plazos establecidos en el DNU. 
lógica y se presenta en un contexto histórico que es distinto para cada Estado, y es mantenida por situaciones de iure (desigualdades entre nacionales y extranjeros en las leyes) y de facto (desigualdades estructurales). Esta situación conduce al establecimiento de diferencias en el acceso de unos y otros a los recursos públicos administrados por el Estado». ${ }^{8}$

Según los estándares del sistema interamericano de derechos humanos, esta situación de vulnerabilidad trae aparejada la obligación del Estado de adoptar medidas de acción positivas acordes, toda vez que la igualdad de trato en circunstancias dispares comportaría un acto discriminatorio en razón del estatus migratorio, ${ }^{9}$ sobre todo respecto de las garantías del debido proceso. ${ }^{10}$ Como destacó la $\mathrm{CIDH}$, «con frecuencia esta clase de procedimientos [de expulsión] se caracteriza por un alto grado de arbitrariedad estatal, frente a la cual las personas migrantes tienen un margen de respuesta mínimo, cuando no nulo. A menudo estos procedimientos tienen múltiples obstáculos, tanto de iure como de facto, que impiden el goce de los derechos de los migrantes en un plano de igualdad con los nacionales». ${ }^{11}$

Es decir, que las disposiciones del ordenamiento jurídico destinadas a procedimientos comunes, y no especiales, como sí lo era la Ley de Migraciones antes de la última reforma, podrían no ser acordes, toda vez que no fueron creadas a la luz de las particulares dificultades que afronta el colectivo de migrantes. En dicho contexto, cabe destacar que, incluso antes de la introducción del DNU 70/17, el Comité de Protección de los Derechos de Todos los Trabajadores Migratorios y de sus Familiares, en sus observaciones finales, resaltó la discriminación estructural sufrida por las personas migrantes durante los procesos de expulsión. ${ }^{12}$

El DNU 70/17 vino a modificar una ley adoptada luego de años de debates y acuerdos políticos, para ser aplicada de manera integral en favor de un grupo en situación de vulnerabilidad dentro de la sociedad (Canelo, Gavazzo y Nejamkis, 2018: 164; Carril, 2018: 198-199). De la demanda de tal especificidad es que el Poder Legislativo adoptó un procedimiento para los casos de expulsiones que respondía al cumplimiento de los tratados de derechos humanos. ${ }^{13}$ Estas consideraciones son de gran importancia si tenemos en cuenta que, según el artículo 29 de la $\mathrm{CADH}$, «ninguna disposición de la [...] Convención puede ser interpretada en el sentido de [...] b) limitar el goce y ejercicio de cualquier derecho o libertad que pueda estar reconocido

8. Corte IDH, opinión consultiva OC-18/03, párrafo 112.

9. Caso Vélez Loor con Panamá, Corte IDH, párrafo 248.

10. Comisión Interamericana de Derechos Humanos, OAS/Ser.L/V/II.155, p. 50.

11. Comisión Interamericana de Derechos Humanos, OEA/Ser.L/V/II.Doc. 46/15, pp. 143-144.

12. "Consideration of reports submitted by States parties under article 74 of the Convention», Comité de Protección de los Derechos de Todos los Trabajadores Migratorios y de sus Familiares, CMW/C/ ARG/CO/1, párrafos 17 y 23, disponible en http://bit.ly/2tS2CbO.

13. El artículo 3 de la Ley de Migraciones hace especial referencia a estas cuestiones en sus incisos e-h. 
de acuerdo con las leyes de cualquiera de los Estados partes». Este artículo recepta el principio pro persona (Estrada, 2015: 44; Rodríguez, 2014: 711), el cual obliga a los Estados a adoptar la norma y la interpretación de ella más favorable a la persona (Pinto, 1997: 163).

El DNU 70/17 invoca a la CADH, y la jurisprudencia de la Corte IDH, como fundamentos que sustentan su sanción, y afirma en forma categórica que el procedimiento sumarísimo es respetuoso de ellas (considerandos 7 y 22). Sin embargo, las normas de interpretación de la $\mathrm{CADH}$ dictan que el Estado no podría invocarla en la limitación del goce de un derecho mejor reconocido en la normativa interna del Estado (Comune y Luterstein, 2013: 531). Ello implica que el Poder Ejecutivo no puede alegar que la reforma del proceso de expulsión de migrantes en Argentina es respetuosa de los derechos humanos, cuando el régimen anterior era más beneficioso.

\section{Vulneración del debido proceso y afectación del acceso a la justicia}

La Corte IDH reconoció que los Estados pueden establecer mecanismos de control de ingreso y salida de su territorio, siempre que dichas políticas sean respetuosas de los derechos humanos de las personas migrantes. ${ }^{14}$ En concordancia, y particularmente en materia recursiva, dicha Corte también señaló que incluso en materia administrativa, la discrecionalidad del Estado tiene como límite infranqueable el respeto de los derechos humanos, ya que «no puede invocar el orden público para reducir discrecionalmente las garantías de los administrados». ${ }^{15}$ Este estándar debe ser respetado con todas las personas migrantes bajo la jurisdicción del Estado, para que «tengan la posibilidad de hacer valer sus derechos y defender sus intereses en forma efectiva y en condiciones de igualdad procesal con otros justiciables». ${ }^{16}$ En particular, el Estado «debe cumplir con las siguientes garantías: i) solo podrá expulsarse a un extranjero en cumplimiento de una decisión adoptada conforme a la ley, y ii) se debe facultar al extranjero la posibilidad de: a) exponer las razones que lo asistan en contra de su expulsión; b) someter su caso a revisión ante la autoridad competente, y c) hacerse representar con tal fin ante ellas». ${ }^{17}$ Es este último punto y sus tres componentes lo que no sería respetado mediante el procedimiento sumarísimo.

El DNU 70/17 fue promulgado bajo el argumento de una emergencia pública imperante, la cual no solo estigmatiza al grupo en cuestión mediante la tergiversación de datos estadísticos (Basok, 2017: 7; Canelo, Gavazzo y Nejamkis, 2018: 165-167;

14. Caso de Personas dominicanas y haitianas expulsadas con República Dominicana, Corte IDH, párrafo 350 .

15. Caso Baena Ricardo y otros con Panamá, Corte IDH, competencia, párrafo 126.

16. Caso Nadege Dorzema y otros con República Dominicana, Corte IDH, párrafo 157.

17. Nadege Dorzema y otros con República Dominicana, párrafo 161. 
González y Tavernelli, 2018: 86), sino que también se refiere de forma exclusiva a ésta como la culpable de las demoras en la resolución de los trámites (véase los considerandos del DNU 70/17), cuando según la ley argentina es el propio Estado quien debe impulsar e instruir de oficio (Ley de Procedimiento Administrativo, artículo 1, inciso a). Por ello, la modificación radical del plazo de quince días para la interposición de un recurso jerárquico — dejando a su vez de lado los de reconsideración y alzada ${ }^{18}$ y treinta días para el recurso judicial, a uno de tres días hábiles, que además resulta improrrogable, no solo es violatoria del derecho al acceso a un recurso efectivo, sino que también es una violación de las garantías procesales.

El debido proceso y el acceso a la justicia se encuentran compuestos por un conjunto de derechos y garantías que son necesarios para materializar su cumplimiento. Para la Corte IDH, el artículo 8.2 de la CADH protege el derecho de contar con tiempo y medios adecuados para preparar una defensa, acceder a los expedientes y analizar las pruebas presentadas en contra de la persona. ${ }^{19}$ En particular, respecto de los procesos migratorios, reconoció que «se vulnera el derecho a las garantías y a la protección judicial por varios motivos: por el riesgo de la persona cuando acude a las instancias administrativas o judiciales de ser deportada, expulsada o privada de su libertad, y por la negativa de la prestación de un servicio público gratuito de defensa legal a su favor». ${ }^{20}$ Es decir, el Estado debe garantizar que el acceso a la justicia sea no solo formal, sino real.

Es notable cómo los recursos regulados por el procedimiento sumarísimo se tornan meramente formales y no reales, ya que a la persona migrante le queda un acotado margen para ver garantizado su derecho de defensa. Tal es así que, desde el momento de la notificación de la disposición que declara irregular su permanencia en el territorio argentino, la persona cuenta por única vez con el beneficio de interrumpir el plazo para recurrir mediante la toma de vista del expediente. Asimismo, en ese plazo, de necesitar asistencia letrada gratuita, deberá acreditar fehacientemente su situación de pobreza ante la DNM para acceder a un patrocinio letrado. Luego, el pa-

18. El artículo 9o de la Ley 25.871, que disponía el recurso de revisión de los actos firmes, era más amplio que el artículo 22 de la Ley 19.549, por cuanto permitía la revisión en casos de error, omisión o arbitrariedad manifiesta, violaciones al debido proceso, o cuando hechos nuevos justifiquen dicha medida.

19. Caso Barreto Leiva con Venezuela, Corte IDH, fondo, reparaciones y costas, párrafo 54. Si bien el caso citado versa sobre un procedimiento penal, la Corte IDH determinó que «el numeral 2 del artículo 8 de la Convención se aplica a [...] la determinación de derechos y obligaciones de orden «civil, laboral, fiscal o de cualquier otro carácter». [...] el individuo tiene el derecho al debido proceso entendido en los términos del artículo 8.1 y 8.2, tanto en materia penal como en todos estos otros órdenes» (Caso Baena Ricardo y otros con Panamá, párrafo 125).

20. Corte IDH, OC-18/03, de 17 de septiembre de 2003, solicitada por los Estados Unidos Mexicanos sobre la Condición Jurídica y Derechos de los Migrantes Indocumentados, párrafo 126. Disponible en https://www.acnur.org/fileadmin/Documentos/BDL/2003/2351.pdf. 
trocinio podrá analizar el expediente y las circunstancias de facto que lo rodean para armar una defensa en el recurso, que en caso de ser infundado o presentado ante la justicia in pauperis forma deberá ser rechazado in limine (artículo 16 del DNU 70/17).

La Corte IDH remarca la «importancia de la asistencia letrada en casos [...] en que se trata de una persona extranjera, que puede no conocer el sistema legal del país», ${ }^{21}$ y enfatizó que «impedir a la persona sometida a un proceso administrativo sancionatorio de contar con la asistencia de su abogado defensor es limitar severamente el derecho a la defensa, lo que ocasiona desequilibrio procesal y deja al individuo sin tutela frente al ejercicio del poder punitivo». ${ }^{22}$ Tal es el deber del Estado para con los migrantes en los procesos de expulsión, que «la asistencia jurídica gratuita se vuelve un imperativo del interés de la justicia». ${ }^{23}$

La gravedad de las reformas introducidas en el DNU 70/17 incluso llamó la atención del Comité contra la Tortura de las Naciones Unidas, según el cual la reducción de los plazos recursivos, sumado a la exigencia de justificar de forma fehaciente la falta de ingresos para acceder al patrocinio letrado, dificultan seriamente el acceso a la justicia de las personas migrantes sometidas al proceso de expulsión. ${ }^{24}$

Es evidente, entonces, que el plazo de tres días hábiles para recurrir en forma fundada - procurando un patrocinio jurídico gratuito- no parece cumplir con los objetivos de la Ley 25.871, el artículo 8.2.c de la CADH y el artículo 25 de la CADH, sino que más bien pretende privar a un colectivo tradicionalmente considerado vulnerable del derecho de acceso a la justicia y debido proceso.

Lo dicho hasta el momento es suficiente para demostrar que la reducción de los plazos configura sin dudas una violación de los artículos 8 y 25 de la CADH. Sin embargo, a ello debe sumarse que a la DNM, a través del DNU 70/17, se le atribuyó la facultad exclusiva de otorgar una dispensa por razones de unidad familiar, mientras que se impide de forma expresa su otorgamiento por la vía judicial. Tal decisión también constituye una negativa del acceso a la justicia y una violación del debido proceso.

$\mathrm{Al}$ respecto, la Corte IDH ha sostenido que los procedimientos administrativos o judiciales que determinen los derechos de personas migrantes a cargo de menores de edad se deben regir por el interés superior, y ajustarse a sus condiciones, necesidades y derechos. ${ }^{25}$ Aunque la Corte IDH reiteró el derecho de los Estados a elaborar y ejecutar sus políticas públicas, en su jurisprudencia ha hecho especial énfasis en que

21. Vélez Loor con Panamá, párrafo 132.

22. Caso Cabrera García y Montiel Flores con México, Corte IDH, párrafo 155.

23. Vélez Loor con Panamá, párrafo 146.

24. Comité Contra la Tortura, Observaciones finales sobre los informes periódicos quinto y sexto combinados de la Argentina, 24 de mayo de 2017, CAT/C/ARG/CO/5-6, párrafo 33.

25. Corte IDH, opinión consultiva OC-21/14, párrafo 115. 
la participación de los niños adquiere especial relevancia cuando se trata de procedimientos que puedan tener carácter sancionatorio, en relación con una infracción al régimen migratorio, abiertos contra niños migrantes o contra su familia, sus padres, representantes o acompañantes, pues este tipo de procedimientos pueden derivar en la separación de la familia y en la subsecuente afectación del bienestar de los niños. ${ }^{26}$

Se observa cómo el DNU 70/17 va en contra de los estándares del sistema interamericano de derechos humanos y adopta una política regresiva al impedir la plena participación en todas las instancias posibles de las niñas, niños y adolescentes, que tienen el derecho - y el Estado una obligación correspondiente- de ser oídos tanto en procedimientos administrativos como judiciales (Muñoz, 2017: 35). Esto se debe a que la modificación de la Ley de Migraciones hace que la decisión discrecional de la DNM de no otorgar una dispensa por motivos de unidad familiar sea inapelable en sede judicial.

Lo hasta aquí planteado resulta relevante porque la dispensa por motivos de unidad familiar se apoya en principios que también son de orden público en Argentina (Elías y Da Silva, 2018), como los derechos de la niñez y la familia (Barreyro, 2018). De allí que el Poder Ejecutivo no pueda limitar dicha dispensa a la etapa administrativa y despojar a la familia, particularmente los niños, de un potencial proceso judicial que les permita expresar las consecuencias de la expulsión.

\section{Sobre el ejercicio del control de convencionalidad contra el DNU 70/17}

Los Estados tienen la obligación ejercer un «control de convencionalidad» ex officio entre las leyes domésticas y la CADH. ${ }^{27}$ Dicha obligación, que sin dudas corresponde a los órganos de la administración de la justicia, ${ }^{28}$ se extiende también a los poderes Legislativo y Ejecutivo. ${ }^{29} \mathrm{~A}$ su vez, este control incluye la interpretación de la Corte IDH en ejercicio de su competencia tanto contenciosa como consultiva, ${ }^{30}$ y no solo respecto de sus sentencias relativas al Estado particular, sino todas ellas, ya que tienen un efecto erga omnes entre todos los Estados partes. ${ }^{31}$

$\mathrm{El} \mathrm{DNU} \mathrm{70/17,} \mathrm{al} \mathrm{ir} \mathrm{contra} \mathrm{los} \mathrm{estándares} \mathrm{del} \mathrm{sistema} \mathrm{interamericano} \mathrm{de} \mathrm{derechos}$

26. Caso Familia Pacheco Tineo con Bolivia, Corte IDH, párrafo 227.

27. Caso Almonacid Arellano y otros con Chile, Corte IDH, párrafos 124-125.

28. Caso Cabrera García y Montiel Flores con México, Corte IDH, párrafo 225.

29. Caso Gelman con Uruguay, Corte IDH, párrafo 193.

30. Corte IDH, OC-21/14, de 19 de agosto de 2014, solicitada por la República Argentina, la República Federativa de Brasil, la República del Paraguay y la República Oriental del Uruguay sobre los Derechos y Garantías de Niñas y Niños en el Contexto de la Migración y/o en Necesidad de Protección Internacional, párrafo 31. Disponible en https://www.acnur.org/5b6ca2644.pdf.

31. Caso Gelman con Uruguay, supervisión de cumplimiento de sentencia, párrafo 69. 
humanos, no supera el control de convencionalidad. La promulgación de la reforma atacó de manera directa el corazón de la Ley de Migraciones: el reconocimiento del derecho humano a migrar. Este derecho, que es superador respeto de los derechos reconocidos en la $\mathrm{CADH}$, si bien no fue modificado en el texto, se torna severamente disminuido ante las restricciones introducidas.

La instauración del procedimiento sumarísimo no solo implica la imposibilidad material de preparar una defensa adecuada, sino que también impide el acceso a la asistencia letrada necesaria para preparar dicha defensa, ya que el procedimiento y los recursos se tornan ilusorios. Por su parte, el impedimento al Poder Judicial de revisar y otorgar la dispensa por motivos de unidad familiar atenta tanto contra los derechos de la persona sometida al proceso de expulsión como de su familia, y en particular sus hijos.

La situación de vulnerabilidad de las personas migrantes en Argentina ha sido ampliamente comprobada por estudios de la doctrina, jurisprudencia e informes de organismos internacionales citados a lo largo de este trabajo. De allí que el Estado no pueda basar la reforma solo en su facultad de regular la política migratoria. A contrario, el Estado requiere de motivos muy serios para poder restringir las garantías de un grupo en especial situación de vulnerabilidad, que era portador de un mejor derecho reconocido por la ley interna. Tales motivos fueron desacreditados y demostraron ser falsos de manera amplia. Ello torna al DNU 70/17 nulo de nulidad absoluta y, por ende, responsable internacionalmente al Estado argentino por las consecuencias de su sanción y aplicación.

Resulta imposible no pensar que el Estado ha adoptado una actitud hostil contra la población migrante. Este fenómeno, lamentablemente, se da en un contexto mundial de creciente estigmatización de las personas migrantes (Baele y Sterck, 2015: 1.133; Basok, 2017: 1; Geddes y Scholten, 2016: 20), que terminan por ser una herramienta del discurso político.

Si bien el fallo de la Cámara de Apelaciones resulta una victoria frente al avance sobre los derechos de las personas migrantes, no es lo suficientemente contundente y deja la puerta abierta a otros mecanismos legislativos que podrían legitimar el contenido a la reforma. La Corte Suprema tiene ahora la oportunidad de reestablecer la óptica de derechos humanos en la política migratoria argentina, que con tanto sacrificio los distintos componentes de la sociedad argentina colaboraron en construir. Las personas migrantes son un elemento indispensable de la sociedad, sobre todo en un país como Argentina, construido en gran medida por su arduo trabajo. Si no se garantizan sus derechos, entonces jamás será la sociedad justa y equitativa que desde su independencia ha pretendido ser. 


\section{Conclusiones}

La Ley de Migraciones no solo significó un paso histórico para Argentina, sino para toda la región. El reconocimiento del derecho a migrar como un derecho humano puso un freno contundente al arrastre de las políticas migratorias demonizantes, características de las dictaduras latinoamericanas.

La situación de vulnerabilidad de las personas migrantes en América llevó al sistema interamericano de derechos humanos a destacar la obligación reforzada del Estado en adoptar políticas públicas y legislaciones que coloquen a este grupo en una situación de igualdad frente al resto de la sociedad. Ese llamado fue escuchado por el Estado argentino en el año 2004, pero, doce años más tarde, parece haber desoído ese llamado, tornando el derecho humano a migrar en una promesa vacía de contenido.

El DNU 70/17 representa un claro retroceso en materia de garantía de los derechos humanos de las personas migrantes. Fue promulgado bajo el escudo de una emergencia pública cuanto menos cuestionable, y colocó la responsabilidad del Estado en el mismo grupo, considerándolo culpable de las demoras existentes en el sistema de la administración pública.

Como he intentado demostrar, el DNU 70/17 se traduce, a la luz de los estándares del sistema interamericano de derechos humanos, en una clara violación del derecho de defensa de las personas migrantes durante los procesos de regularización migratoria -en particular frente a la expulsión-, en la negación del acceso a la justicia, y la vulneración del derecho al debido proceso de las personas migrantes y sus familias. Por ello, la reforma migratoria impuesta por el Poder Ejecutivo en Argentina no supera el control de convencionalidad que el Estado debe garantizar.

Argentina aún tiene la posibilidad de remediar su conducta en sede interna. El pronunciamiento de la Corte Suprema se encuentra aún pendiente de resolución. ¿Será ésta una oportunidad para observar la real naturaleza subsidiaria del sistema interamericano, o una vez más las personas migrantes tendrán que acudir a la instancia internacional para ver garantizados sus derechos?

\section{Agradecimientos}

Quisiera expresar el profundo agradecimiento a mi querida amiga María Soledad da Silva, cuyos comentarios y críticas fueron indispensables en la conclusión de este trabajo. Asimismo, agradezco especialmente a Camila Carril, junto al equipo de la Subdirección de Migrantes de Defensoría del Pueblo de la Ciudad de Buenos Aires, por el constante apoyo, y a Pablo Colmegna, quien con sus discusiones me impulsó a desarrollar el presente análisis. 


\section{Referencias}

Avalos, Eduardo (2012). «Los decretos de necesidad y urgencia en Argentina: Desde 1853 hasta nuestros días». Revista de la Facultad, 3 (1): 147-157. Disponible en http://bit.ly/2sir2Lo.

BAELE, Stephane y Olivier Sterck (2015). «Diagnosing the securitisation of immigration at the EU level: A new method for stronger empirical claims». Political Studies, 63 (5): 1.120-1.139. DOI: 10.1111/1467-9248.12147.

BARBERO, María (2018). «Immigration policyand belonging in the Argentine «racialstate»». Journal of Ethnic and Migration Studies. DOI: 10.1080/1369183X.2018.1544486.

Barreyro, María (2018). "Nuevas políticas migratorias como medidas de política criminal. Análisis de casos». Ab: Revista de Abogacía, 2: 7-12. Disponible en http:// bit.ly/34ZqgQr.

BAsoK, Tanya (2017). «Regional migration and Argentina's «hospitality» in crisis». En Cecilia Menjívar y otros (editores), The Oxford handbook of migration crises. Oxford: Oxford University Press.

Canelo, Brenda, Natalia Gavazzo y Lucila Nejamkis (2018). «Nuevas (viejas) políticas migratorias en la Argentina del cambio». Si Somos Americanos: Revista de Estudios Transfronterizos, 18 (1): 150-182. DOI: 10.4067/So719-09482018000100150.

CARril, Camila (2018). «Política migratoria argentina: El rol de las Defensorías del Pueblo como instituciones de garantía de derechos humanos». Redea: Derechos en Acción, 8 (8): 195-233. DOI: 10.24215/25251678e179.

Ceriani, Pablo (2011). «Luces y sombras en la legislación migratoria latinoamericana». Nueva Sociedad, 233: 68-86. Disponible en http://bit.ly/2SHRwkj.

Comune, Josefina y Natalia Luterstein (2013). «Artículo 29: Normas de Interpretación». En Enrique Alonso Regueira (director), La Convención Americana de Derechos Humanos y su proyección en del derecho argentino. Buenos Aires: La Ley.

ELÍAs, Victor y María Soledad da Silva (2018). «El derecho a la protección de la vida familiar y el interés superior del niño en los procedimientos de extradición en Argentina». En Silvina González Napolitano (directora), Estándares internacionales de protección de los derechos humanos aplicables al instituto de extradición: Su incidencia en la práctica argentina. Buenos Aires: SGN.

Estrada, Guillermo (2015). La interpretación de la Convención Americana sobre Derechos Humanos: Una revisión desde la fragmentación del derecho internacional. Ciudad de México: CNDH.

García, Lila (2013). «Estándares migratorios en el Sistema Interamericano de Derechos Humanos y derecho a migrar en Argentina». Revista Derechos Humanos, 2 (2): 39-76. Disponible en http://hdl.handle.net/11336/23319.

GedDEs, Andrew y Peter Scholten (2016). The policies of migration and immigration in Europe. Londres: SAGE. 
GonZÁLEZ, Anahí y Romina Tavernelli (2018). «Leyes migratorias y representaciones sociales: El caso argentino». Autoctonía, 2 (1): 74-91. DOI: 10.23854/autoc.v2i1.49.

Hines, Barbara (2010). «The right to migrate as a human right: The current Argentine Immigration Law». Cornell International Law Journal, 43 (3): 471-511. Disponible en http://bit.ly/2EXKFef.

Mendos, Lucas y Rosario Muñoz (2012). «Garantías procesales en procesos de expulsión de migrantes». En Sebastián Rey (editor), Problemas actuales de derechos humanos 1. Buenos Aires: Eudeba.

MuÑoz, Rosario (2017). «La potestad de dispensa por razones de índole familiar, como facultad discrecional - exclusiva- de la Dirección Nacional de Migraciones». Estudios de Jurisprudencia, 2017 (3): 20-36. Disponible en http://bit. $1 y / 37 \mathrm{cNtAg}$.

NeJAmKis, Lucila (2012). «Políticas migratorias en tiempo kirchneristas (2003-2010): ¿Un cambio de paradigma?». En Susana Novick (directora), Migración y políticas públicas: Nuevos escenarios y desafíos (pp. 89-115). Buenos Aires: Catálogos.

NiCOlAO, Julieta (2010). «El Estado argentino ante el reto de las migraciones internacionales: Reflexiones del reciente cambio de rumbo en la política migratoria argentina». Convergencia, 17 (53): 205-228. Disponible en http://bit.ly/2Qobsgm.

PInTo, Mónica (1997). «El principio pro homine: Criterios de hermenéutica y pautas para la regulación de los derechos humanos». En Martín Abregú y Christian Courtis (compiladores), La aplicación de los tratados sobre derechos humanos por los tribunales locales. Buenos Aires: Del Puerto.

RodrígueZ, Gabriela (2014). «Artículo 29: Normas de interpretación». En Christian Steiner, y Patricia Uribe (coordinadores), Convención Americana sobre Derechos Humanos Comentada. Ciudad de México: Konrad Adenauer.

\section{Sobre el autor}

Víctor LisAndro Elí́As es auxiliar docente de la Universidad de Buenos Aires, candidato al LL.M. en International Law en el Graduate Institute of International and Development Studies de Ginebra, Suiza. Es abogado en la Subcoordinación Operativa de Migrantes y Refugiados de la Defensoría del Pueblo de la Ciudad Autónoma de Buenos Aires, defendiendo y asesorando tanto en procesos administrativos y judiciales. Su correo electrónico es eliasvld@gmail.com. 
